\title{
Assessing the Feasibility of a Parent Life Coaching Intervention to Support Parents and Children Who Have Experienced Domestic Violence and Abuse
}

\author{
Vashti Berry ${ }^{1,2} \cdot$ Kath Wilkinson $^{2} \cdot$ Nina Farr $^{3} \cdot$ Anna Stimson $^{2}$
}

Published online: 5 March 2019

(C) The Author(s) 2019

\begin{abstract}
Children exposed to domestic violence are at risk for a range of psychosocial difficulties, which may be mitigated by improving their caregiver's mental health and capacity to parent. Life coaching is a promising behaviour change approach for improving the empowerment, efficacy and well-being of carers who are parenting alone following domestic violence. This study evaluated the feasibility of a novel life coaching programme. Using a pre- post-test design, the Family Vision@ (FV) programme was implemented in two community settings. The programme was offered to single mothers with experience of domestic violence. Feasibility data were collected using satisfaction forms, semi-structured interviews and focus groups with parents, facilitators and managers. Mothers' self-reports about their mental well-being; empowerment and self-efficacy were collected, as well as the quality of their parent-child relationships and children's psychosocial functioning, using standardised measures at baseline and end of programme. The programme was found to have good acceptability for this population of parents and was considered feasible to deliver in the two community settings where it was piloted. There were indications that women who completed the programme had improved mental well-being, as well as improved empowerment and efficacy by the end of the programme. The FV programme is feasible to implement and could support positive change for single parents with respect to their mental health and capacity to parent effectively. Demonstrated mediators, these effects could also promote children's health and well-being. Feasibility for a randomised trial and wider scale-up in the community is now required.
\end{abstract}

Keywords Domestic violence $\cdot$ Children $\cdot$ Life coaching $\cdot$ Feasibility $\cdot$ Empowerment

\section{Introduction}

Domestic violence and abuse (DVA) includes “any incident or pattern of incidents of controlling, coercive, threatening behaviour, violence or abuse between those aged 16 or over who are, or have been, intimate partners or family members regardless of gender or sexuality. The abuse can encompass but is not limited to: psychological, physical, sexual, financial and emotional"

\section{Vashti Berry}

V.Berry@exeter.ac.uk

1 NIHR CLAHRC South West Peninsula, University of Exeter, Exeter, UK

2 Institute for Health Research, College of Medicine and Health, University of Exeter, Room 2.02, College House, St Luke's Campus, Exeter EX1 2LU, UK

3 Get Up and Grow, Ltd. And Family Vision CIC, Tavistock, Devon, UK
(Gov.UK 2017). While this may affect both men and women, the gendered nature of family violence is widely acknowledged and women are more likely to experience all forms of abuse and to be injured as a result. Children who have been exposed to DVA - including those who witness it, are directly involved in it, as well as those who may or may not be aware of the abuse of their caregiver - will be at significant risk for social, emotional and behavioural difficulties, even after they have left the violent family context (Evans et al. 2008; Kitzmann et al. 2003; Wolfe et al. 2003). This risk to children's health and development may be conferred directly through the trauma of witnessing the violence and its impact on their mother, as well as indirectly through its harmful effects on the mental health of caregivers and the parenting and relationships they are subsequently able to provide to children (Graham-Bermann and Perkins 2010). In particular, mothers who survive DVA are at greater risk than their non-abused peers for emotional disorders, particularly major depression; employing inconsistent or harsh parenting styles; and are more likely to report reduced 
empowerment or control in their parenting role (Austin et al. 2018; Lapierre 2010a, b; Letourneau et al. 2007; Stein and Kennedy 2001; Zlotnick et al. 2006).

Not all children exposed to domestic abuse fare badly, however. There is evidence to suggest that the quality of the primary parent-child relationship and the parenting provided, as well as the parent's (mother's) mental health and well-being can mitigate negative outcomes for children (GrahamBermann and Perkins 2010; Letourneau et al. 2001). Thus, an obvious intervention opportunity is to provide psychological and/or parenting support to parents who have left violent relationships. The recent IMPROVE evidence synthesis suggests that, in the context of limited robust evidence about what works for children exposed to DVA, group-based psychoeducation and parenting skills training combined with advocacy may be the best candidates for effective intervention (Howarth et al. 2016).

While parenting programmes are widely available in a UK context, those routinely offered in community and family service settings, even when targeted, do not typically identify abuse or address the impact that it may have had on the parent or child (Guy et al. 2014). In addition, the focus on children's difficulties may relegate the needs of the abused mother to the sidelines or worse still, emphasise failings or deficiencies in their parenting (Lapierre 2008). There is a strong case to explore whether generic (widely available) parenting skills programmes - commonly prescribed to respond to children's behavioural and psychosocial difficulties - are acceptable and effective for this population, and what adaptations may be required to tailor them appropriately (e.g. Guy et al. 2014; Jack et al. 2012), but we should also consider complementary and supplementary interventions that family support workers can provide to address the consequences of DVA on mothers, and improve their engagement with, and the impact of, generic parent training.

\section{Life-Coaching}

Life coaching is defined as a "motivational and behavioural change approach that helps people to set and reach better goals, leading to enhanced well-being and personal functioning" (Jarosz 2016, p. 34). Grounded in cognitive behavioural, humanistic and positive psychology theories, it has been used to effect behaviour change in physical and mental health, employment and education by providing a method and relationship within which individuals can develop their ability to identify, prioritise and engage with life goals they want to achieve. Life coaches help people to deconstruct feelings and distorted thoughts, consider alternative interpretations and views about the world, and improve decision making (Stober and Grant 2006).

While the approach has developed rapidly since the 1990s, attracting both recognition and criticism (Jarosz 2016), evidence from robust studies or trials of life coaching interventions is limited. A recent systematic review of available studies suggests it is a promising supplementary approach for improving health outcomes, via improved selfempowerment and self-efficacy, especially for those from disadvantaged backgrounds (Ammentorp et al. 2013). A significant limitation in the life coaching literature to date is the lack of consistency in definition; studies need to better describe and categorise the coaching methods they use to enable comparison and synthesis (Ammentorp et al. 2013; Jarosz 2016). Notwithstanding, a life coaching model that delivers improved empowerment and self-efficacy to parents and helps them re-evaluate and strengthen their relationship with their children is likely to be a promising supplementary service to support families affected by DVA.

\section{The Family Vision@ Programme}

Family Vision (FV) was designed to apply life coaching methods in the context of single ${ }^{1}$ parenthood following family breakdown due to DVA (Farr 2017, 2018). It was developed in response to the lack of strengths-based support available for survivors in their role as parents, particularly mothers who are most often the victims of DVA. FV uses life coaching, as outlined above, as well as elements of women's leadership coaching, which applies coaching to the unique problems experienced by women aspiring to be leaders in industry enabling them to develop their capabilities in strategising and executing plans, claiming authority, and building confidence and selfesteem (Leimon et al. 2011). The purpose in combining these approaches in the FV programme is to enable parents to take ownership of their own experiences and give more time to listening to parents' perspectives, rather than imposing a service provider perspective. Facilitators engage parents with questions, rather than teaching them principles or ideas deemed to be of value, and reflect back what has been said by the parent, to enable them to re-process their dialogue and to take charge of their internal narrative. In so doing, women directly experience being the authority on their own life and family situation (effectively the Chief Executive Officer of their family), which allows them to be better able to engage with services and participate as equal partners in their children's recovery, when required.

The programme draws on the principles of trauma-informed approaches to care, which assume that people who have experienced trauma may find it difficult to develop trusting relationships with providers, and require collaboration, choice and control to feel safe within services (SAMHSA 2014). While all FV participants will have past trauma as a common experience, life coaching is a recovery and reintegration approach for families in a position to rebuild their lives following abuse. It is not an

\footnotetext{
${ }^{1}$ We use the term 'single' parent to denote parents who are the sole resident carer for their child/ren, where the child's other parent is non-resident, absent or in irregular contact. Single parents may be in other intimate relationships but this does not include cohabiting partnerships.
} 
approach for families in crisis or those requiring significant therapeutic input to treat trauma.

Family Vision is a manualised 11-week intervention, designed to be delivered face to face with a group of 8-12 parents, in community-based children's services' settings. Weeks one and two of the programme serve as 'settling in' sessions for the parents to get to know one another and the FV facilitators, and for the children who are attending the crèche to feel at ease with workers. The remaining nine sessions comprise coaching (content) sessions, focusing on a pre-specified key question or idea each week, supported by handouts and homework exercises. The programme is mapped against a well-established coaching cycle (Cummings and Worley 2009), beginning with a period of guided self-assessment of their skills and attributes; leading into a planning stage where they set goals; an active stage and a reflective stage. It culminates in celebrating individual progress and re-evaluating where each parent feels they are now. Each session is run on a predictable format, beginning with a welcome, check in, followed by two activities interspersed with a break, before roundup and closure. For larger groups, facilitators will introduce the activities then split parents into smaller breakout groups. The programme is delivered by a lead accredited facilitator and supported by at least one cofacilitator, who may still be in training. Table 1 details the thematic content of the programme, and indicates the stage of the coaching cycle to which it corresponds, as well as how its focus relates to the overall parent leadership approach.

\section{Research Aims and Questions}

The aims of the current study were to assess the feasibility, acceptability and promise of the Family Vision programme to improve the well-being and parent leadership capabilities in single mothers caring for children who have experienced domestic violence. Specifically, the objectives were to explore whether:

1. Family Vision is feasible to deliver, including the ability to recruit and retain participants in universal or community settings that families access.

2. Family Vision is acceptable to parent participants, new facilitators trained to deliver the intervention, and senior managers hosting the programme in their sites.

3. Family Vision has the potential to improve mothers' mental health and well-being, efficacy and empowerment, such that it could improve the quality of the parent-child relationship and reduce child psychosocial difficulty in the longer-term.

\section{Methodology}

\section{Study Design}

Using a prospective pre- and post-test design, the Family Vision programme was implemented and evaluated in two sites in Exeter, UK, through universal and community-based children's services (i.e. a Children's Centre, for families with children under 5 years of age, and a primary school for families with children up to age 12). The study protocol was approved by the University of Exeter Medical School Research Ethics Board.

\section{Participant Recruitment and Eligibility}

The Family Vision programme is specifically for lone and single parents, who are the main carer for their children

Table 1 Family Vision: weekly overview and programme cycle

\begin{tabular}{|c|c|c|}
\hline Week & Theme & Coaching Cycle stage and focus \\
\hline $1 \& 2$ & Settling-in sessions & \multirow{4}{*}{$\begin{array}{l}\text { Stage 1: Self-assessment. Reviewing all the elements that contribute to } \\
\text { their experience of parenting today. }\end{array}$} \\
\hline 3 & Leadership: Who am I being? & \\
\hline 4 & Values: What do I value? & \\
\hline 5 & Beliefs: What do I believe? & \\
\hline 6 & Goals: What are my goals? & $\begin{array}{l}\text { Stage 2: Set goals. Exploring how goals have the ability to bond } \\
\text { a family under strong leader. }\end{array}$ \\
\hline 7 & Advocacy: What do I need? & $\begin{array}{l}\text { Stage 3: Prepare. Recognising that power lies in drawing in resources from } \\
\text { outside the family, while creating boundaries around it at the same time. } \\
\text { Commit to taking action. }\end{array}$ \\
\hline 8 & Mind-set: How am I developing? & $\begin{array}{l}\text { Stage 4: Implement. Take purposeful action towards these goals. Identify the } \\
\text { learning occurring in actions taken by the parent today. Develop a growth mindset } \\
\text { when set-backs are experienced, and to support children to do so. }\end{array}$ \\
\hline 9 & Vision: What is my vision? & Stage 5: Reflect. Preparing a vision board with the lens of leadership and personal \\
\hline 10 & Vision building & $\begin{array}{l}\text { responsibility - accommodating parent's potential to develop, while taking } \\
\text { on the responsibility for children's growth and development within family situation. }\end{array}$ \\
\hline 11 & Celebration: Sharing the vision & Return to re-commence Stage 1 \\
\hline
\end{tabular}


following domestic abuse; most often this is mothers but the programme does not exclude fathers, where they share the experience of being single parent victims of DVA. In the current study, the partner service agencies decided to focus on supporting single mothers ${ }^{2}$ in the Exeter conurbation. They were recruited over a four-week period in November and December 2016. They were recruited to a group in a Children's Centre via Family Support Workers, the local area Health Visiting team and Early Help (mental health in schools) team. In addition, the programme was advertised on notice boards and Centre workers were briefed and encouraged to support suitable mothers to apply. A school-family link worker supported known parents to apply to a group held at a primary school and two coffee mornings were held to raise awareness about the programme within the school. The programme was advertised on the Family Vision Facebook page, and self-referrals to the groups were accepted via this route.

Mothers were provided with information about the programme and the study, and had the opportunity to speak to a FV facilitator prior to accepting a place on the programme. Only mothers who fitted the inclusion criteria were invited to attend and take part in the research; no comparison group was recruited for this study. Those who agreed to take part in the research were asked to complete a research consent form. Participation in the research was voluntary and did not affect access to the programme or any other support provided.

\section{Training and Intervention}

Six staff from across the two settings were selected to be trained by the programme developer as FV facilitators, three of whom went on to co-deliver the two groups alongside the developer. All practitioners had received at least basic training in domestic violence and were trained in dealing with disclosure and risk assessment. ${ }^{3}$ The FV training took place over two days prior to the programme commencing. A programme manual was provided to facilitators as well as ongoing support through weekly supervision and feedback after each group delivery session. The training combined experiential and instructive elements, to allow facilitators to both experience the coaching process personally, understand the core activities and develop skills to facilitate a coaching discussion with others.

The Family Vision programme began in early January 2017 at both the Children's Centre and primary school and was delivered over 11 weeks, with weekly sessions each lasting two hours. Applying lessons learned from previous work about user engagement (Axford et al. 2012), we sought to find appropriate times during the day for the groups (when children

\footnotetext{
${ }^{2}$ We use 'mother' and 'parent' interchangeably from here on since the study sample included mothers only.

${ }^{3}$ Disclosures were recorded in writing and shared between the lead facilitator and co-facilitators at the close of each session. A collaborative decision was then made to escalate or monitor the situation.
}

were in school lessons or day care) and provided an on-site crèche for pre-school-aged children at both sites. Food and refreshments were provided each week, as well as assistance with travel to the group where required. Mothers were offered the opportunity to talk to FV facilitators by telephone between sessions about any difficulties or arising challenges; contact with other parents between sessions was not specified but may have occurred.

\section{Data Collection}

We adopted a mixed-methods approach to data collection, gathering both quantitative data using attendance logs and standardised measures, as well as qualitative data through interviews and focus groups. Methods were selected to fit the particular research objectives, as per Table 2 below. We held two parent focus groups, involving a total of six parents and individually interviewed seven additional parents. Three FV facilitators were interviewed as well as a senior manager from each of the two delivery sites.

Feasibility (of the Intervention) We were interested in the factors that hindered or aided parent engagement with the programme, the perceived utility and feasibility of the programme in community contexts, how costs for delivery might be met, and modifications that may improve programme delivery. Fidelity data on adherence of delivery was not gathered since the programme was primarily delivered by the programme developer, following a pre-specified manual. All mothers, FV facilitators and a senior manager (Head Teacher and Centre Manager) from the two sites were invited to take part in a focus group or interview within 3-4 weeks of the end of the programme. Focus groups lasted no longer than two hours and interviews up to one hour. All those participating were offered $£ 15$ of high-street shopping vouchers as an acknowledgement for their time.

Acceptability and Promise Feedback on parent satisfaction with the programme was gathered through weekly feedback forms (scale of 1 to 5 , where 1 is excellent and 5 is poor), and the post-intervention interviews and focus groups also explored satisfaction with the programme, acceptability of the intervention content and utility for parents affected by domestic violence. Facilitators were asked about the quality and usefulness of the training and supervision they received via post-training feedback forms and post-intervention interviews. Interviews also explored whether the programme had affected the facilitators' usual practice.

Pre- and post-intervention outcome measures were administered to the mothers as a questionnaire which took approximately 30-45 min to complete. Questionnaires were selfcompletion but parents were offered support to complete them if preferred. They were given a $£ 5$ high-street voucher at each 
Table 2 Data collection methods

\begin{tabular}{|c|c|c|c|}
\hline Dimension & Data source/s & Methods & Time points \\
\hline Feasibility: recruitment and retention & $\begin{array}{l}\text { Parents } \\
\text { FV facilitators }\end{array}$ & $\begin{array}{l}\text { Agency referral forms } \\
\text { Attendance logs }\end{array}$ & $\begin{array}{l}\text { Pre-intervention } \\
\text { Weekly }\end{array}$ \\
\hline Feasibility: how easy/difficult was it to deliver? & $\begin{array}{l}\text { FV facilitators } \\
\text { Senior managers }\end{array}$ & Interviews and focus groups & Post-intervention \\
\hline Acceptability: do providers and parents like the programme? & $\begin{array}{l}\text { Parents } \\
\text { FV facilitators }\end{array}$ & $\begin{array}{l}\text { Parent weekly feedback forms } \\
\text { Facilitator training feedback } \\
\text { Interviews and focus groups }\end{array}$ & $\begin{array}{l}\text { Weekly } \\
\text { End of training } \\
\text { Post-intervention }\end{array}$ \\
\hline Potential effectiveness: estimates of change & Parents & $\begin{array}{l}\text { Questionnaires with standardised } \\
\text { outcome measures }\end{array}$ & Pre- and post-intervention \\
\hline $\begin{array}{l}\text { Potential effectiveness: what impact did the } \\
\text { programme have? }\end{array}$ & $\begin{array}{l}\text { Parents } \\
\text { FV facilitators }\end{array}$ & Interviews and focus groups & Post-intervention \\
\hline
\end{tabular}

timepoint, in recognition of their time. The measures included in the questionnaires sought to gather demographics and details about their parenting and family situation, including: the number and ages of children; children's contact with another non-resident parent; the mothers' access to emotional, financial and practical support if needed; any current dating relationship/s and the quality thereof; and, their experience of violence and abuse by any previous partner. In addition, four standardised outcome measures were used to examine each parents' well-being and levels of empowerment, the quality of at least one (index) parent-child relationship in the family, as well as the same child's psychosocial functioning:

1. The Parent Empowerment and Efficacy Measure (Freiberg et al. 2014). This measure aims to gauge parents' sense of control or capacity to engage confidently with the challenges of being a parent. It consists of 20 positively worded statements with a rating agreement scale from one to ten.

2. The Warwick-Edinburgh Mental Well-Being Scale (NHS Scotland 2006; Clarke et al. 2011). This measure has been validated for the measurement of mental well-being among people aged 13 to 74 in the UK comprising 14 positively worded statements with five response categories from 'none of the time' to 'all of the time'.

3. The Child-Parent Relationship Scale (Pianta 1992; Driscoll and Pianta 2011). This scale has 15 items that are rated from one to five. The ratings can be summed into groups of items corresponding to conflict (score range 840) and closeness (score range 7-35) subscales.

4. The Strengths and Difficulties Questionnaire (SDQ; Goodman et al. 1998, 2001). This questionnaire is made up of 35 items about child psychosocial functioning, for children aged 3-16 years, which include 25 descriptive statements rated as 'not true', 'somewhat true' or 'certainly true'. It also includes five questions about the impact of any difficulties. A total score of 17 or more is considered likely clinical caseness, a threshold indicating probable clinical disorder.

\section{Data Analysis}

\section{Qualitative Data}

All focus groups and interviews were audio-recorded and transcribed for analysis. Responses were analysed thematically around the topics of feasibility, and acceptability and effectiveness. The feasibility themes examined: the recruitment to the programme; how feasible delivery of the programme was in the community settings; how it compared to other parenting or domestic violence programmes; and, the factors that helped or hindered attendance. Acceptability and effectiveness themes included: how well providers and parents liked the training and the programme; how acceptable the programme was to those with a history of domestic violence; as well as the impact of the programme on current participants.

\section{Quantitative Data}

Data gathered through the pre- and post-intervention questionnaires was entered into a password-protected SPSS file for analysis. SPSS version 22 was used to provide descriptive statistics for each measure, including means and standard deviations at pre- and post-intervention, and a change score with $95 \%$ confidence intervals. Since this was a feasibility study, and scores are only indicative of potential effectiveness, a power calculation was not performed. The percentage of children meeting likely clinical disorder on the SDQ was calculated at pre- and postintervention. Data gathered from the participant weekly feedback forms and FV facilitator training satisfaction questionnaires was also recorded electronically and analysed descriptively.

\section{Results}

\section{Demographics}

Table 3 describes the demographics of the sample of mothers and their children. Where relevant, differences between the 
Table 3 Demographics of the sample

\begin{tabular}{|c|c|}
\hline Parent characteristics & $\begin{array}{l}n=19(\text { All female }) \\
\text { Age range }=21-43 \text { years; } \\
\text { Mean }=32.2 \text { years: } \\
\text { Children's Centre }=29.6 \\
\text { years; School }=38 \text { years }\end{array}$ \\
\hline Violence in previous relationship & $\begin{array}{l}\text { Emotional violence: } n=19 \\
\text { Physical violence: } \mathrm{n}=14\end{array}$ \\
\hline Time parenting alone & $\begin{array}{l}\text { At least } 6 \text { months: } \mathrm{n}=2 \\
1-2 \text { years: } n=4 \\
\text { Over } 2 \text { years }=13\end{array}$ \\
\hline $\begin{array}{l}\text { No or uncertain access } \\
\text { to support from others }\end{array}$ & $\begin{array}{l}\text { Financial support: } n=12(63 \%) \\
\text { Emotional support: } n=3(16 \%) \\
\text { Practical support: } n=8(42 \%) \\
\text { Help with the children: } n=9(47 \%)\end{array}$ \\
\hline Current relationship status & $\begin{array}{l}\text { Single }=12 \\
\text { Ongoing relationship }=7 \\
\quad(4 \text { months }-2 \text { years in length })\end{array}$ \\
\hline $\begin{array}{l}\text { Number of children } \\
\text { per family }\end{array}$ & $\begin{array}{l}\text { Mean }=2.3 \text { children } \\
\text { Range }=1-5 \text { children }\end{array}$ \\
\hline Child characteristics & $\begin{array}{l}n=46(24 \text { male, } 22 \text { female }) \\
\text { Age range }=5 \text { months }-23 \text { years; } \\
\text { Mean }=6.2 \text { years: } \\
\text { Children's Centre }=4.6 \text { years; } \\
\text { School }=8.6 \text { years }\end{array}$ \\
\hline $\begin{array}{l}\text { Child contact }^{\mathrm{a}} \text { with } \\
\text { biological father at } \\
\text { pre-intervention }\end{array}$ & $\begin{array}{l}\text { No contact = } 17 \text { children (from } 8 \\
\text { parents) } \\
\text { Irregular contact }=17 \text { children } \\
\quad \text { (from } 8 \text { parents) } \\
\text { Regular contact }=7 \text { children } \\
\quad \text { (from } 2 \text { parents) }\end{array}$ \\
\hline
\end{tabular}

${ }^{\mathrm{a}}$ Three parents had different arrangements for their multiple children

school-based group and the Children's Centre group are noted. In general, mothers and children in the primary school group were older than the Children's Centre group. All mothers reported experiencing violence in previous intimate relationships, and the majority had been parenting alone for over two years. Most children had irregular or no contact with their father.

\section{Feasibility of the Intervention}

Recruitment and Retention Forty-eight mothers were referred to the programme, many by Family Support Workers or directly from a recently completed women's DVA course delivered through the local Children's Centres $(n=19)$ (Fig. 1). Four mothers were referred by Health Visitors and five were self-referrals. Twenty parents were contacted by the schoolfamily link worker in the primary school and invited to apply. Of the parents intitially approached, one had been inappropriately referred and was ineligible (safeguarding risk), 23 refused and the remaining mothers were offered a space on the programme. Full recruitment to the two FV groups was achieved, with a total of 24 mothers accepting a place; 11 at the primary school and 13 at the Children's Centre. Thus, for every two people referred, one parent was recruited. Only one mother refused participation in the research.

Eighty-three percent $(n=20)$ of mothers offered a space on the course attended at least one of the two settling-in sessions and $17(70 \%)$ completed the 11-week programme. Of those who completed the programme, attendance at the nine coaching (content) sessions was very high, with mothers at the primary school attending an average of 8.1 sessions, and those at the Children's Centre attending on average 7.9 sessions.

Feasibility of Delivery in Universal/Community Settings The direct costs of delivering the Family Vision programme for the present study were covered by the research funder, with provider partners offering their staff facilitators' time in-kind. With regard to future commissioning of the programme, the Head Teacher said that funding could likely be sourced from school Pupil Premium ${ }^{4}$ money, as all the parents on the course had children who were eligible for this funding. Decisions about how to spend the money are made by the school governors and the leadership team, but decisions about what programmes will work with which parents "can only be made through experience" [Head Teacher].

At the Children's Centre, the manager reported that although there is direction from the Local Authority about which parenting programmes they should deliver, there is greater flexibility with other interventions as long as a need can be identified. She admitted that cost often affected decision-making, since choosing to deliver a cost-intensive intervention (in terms of childcare, space etc.) would mean less resource to deliver others. The manager noted that Family Vision seemed a good fit with what she thought many parents needed, stating that: "sometimes the parenting work isn't very effective, because I still see this gap where it isn't possible to parent effectively unless you are able to develop yourself. It feels to me like this could be the missing factor." She went on to say:

Looking outside traditional parenting programmes...

I'm very keen on women developing themselves...

what they need first is some kind of goal... The goal has to be the big motivator. You've got to get them back into thinking about themselves [Centre Manager].

Facilitators and managers were asked about how supportive their host organisations were for delivering FV in their setting. The school facilitator said that the support made "a huge amount of difference" [Facilitator 1]. The Head Teacher was clear that programmes like FV needed to be prioritised, acknowledging that there is a greater need for schools to support families than there used to be. She said:

\footnotetext{
${ }^{4}$ Pupil premium is additional funding for publicly funded schools in England to raise the attainment of disadvantaged pupils of all abilities and to close the gaps between them and their peers.
} 
Fig. 1 Flowchart of recruitment to the programme and research

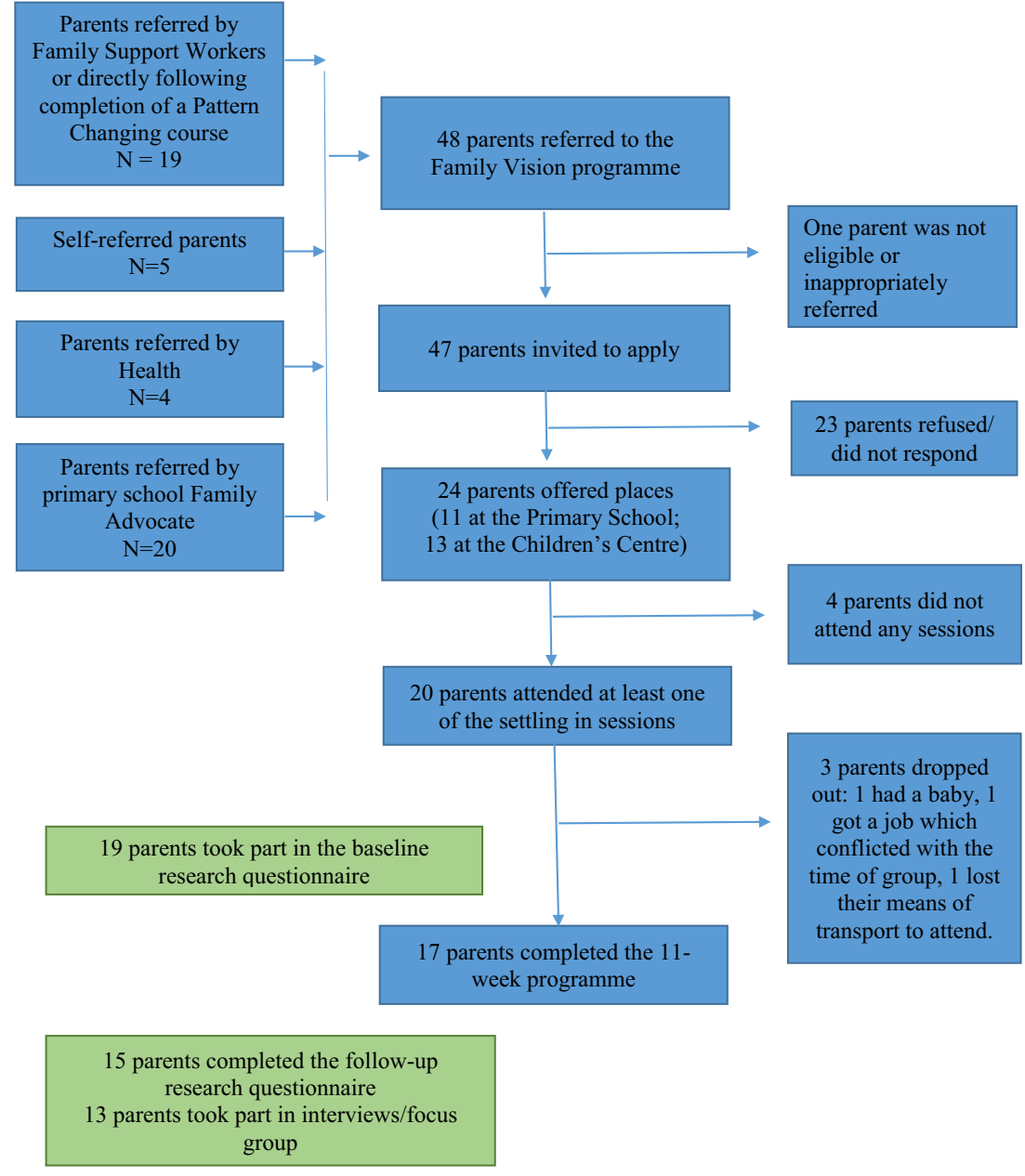

I have to keep reminding myself, particularly in this school, that we are here to teach children and children are here to learn. But actually if you are working in a school where there is that [high] level of need, you need to be really aware that by supporting parents you are going to empower children [Head Teacher].

The Children's Centre manager echoed these sentiments; she thought that "just being consistent about the environment, the facilitators and generally about how something is delivered" was important, as well as making people feel welcome: "thoughtfulness makes such a difference". She thought that targeting the right parents and making sure the wider staff group knew about the programme was also important to ensure successful delivery. The Children's Centre manager felt that the Centre was a good location to hold Family Vision, and suggested that organisations working in the domestic violence sector could also run it.

What Other Interventions are Available for Families? Support provided in the school for children and families exposed to DVA, other than through Family Vision, included one-to-ones for some children, provided by workers from a local charity supporting families affected by DVA, and the school-family link worker working directly with particular children and families. The Children's Centre manager reported that they receive most of their referrals for support from Health Visitors, but that working with the specialist DVA sector was becoming more common. She noted that referrals from Family Support don't often pick up DVA and that disclosure figures increase once workers get to know the family:

We have found on Family Support referrals that the identification of domestic violence is very low. Once we get to know the family, this jumps up to $50-60 \%$. It's only $10-15 \%$ when they are referred. It's rare for a parent to even realise that they have experienced DVA [Centre Manager].

Other programmes provided by the Children's Centre include a range of parenting interventions, such as the Solihull Approach and Incredible Years parenting programme, as well as referral into or joint delivery of specialist 
domestic violence survivor programmes, like the Pattern Changing and Freedom programmes. ${ }^{5}$

Barriers and Facilitators to Attendance Both managers agreed that it was often very difficult to recruit to group-based programmes; one commented: "You [the parents] need a fair degree of confidence to come into a group" [Centre Manager]. The Children's Centre manager said that having settling sessions where the children can try out the crèche and the parents can meet informally first had improved attendance rates. The FV facilitators also found these sessions beneficial but said that it needed to be feasible for the parents involved, taking into account how far they were travelling and if they needed to take time off work to attend. For the school group, where there was less need to settle children into a crèche and activities were added to the second settling session to avoid parents becoming restless.

Other things that mothers and facilitators noted as supporting engagement and retention were: good quality pre-course information, between-session contacts with facilitators and/or other parents, having an approachable and credible leadership coach, and getting on with the other parents in the group. Other practical considerations included childcare and refreshments on arrival. One FV facilitator reported that parents started bringing food to contribute to the group, and took on roles such as cup and coffee monitors, which helped them to get to know each other.

Mothers' non-attendance at individual sessions was reported to be due to sickness, work or other commitments that could not be amended. The Head Teacher noted that approximately half of the parents they had initially referred/invited to the programme did not take up the opportunity and described these families as ones who "don't really engage with anything".

\section{Programme Acceptability and Promise}

Acceptability of the Programme Feedback was gathered from mothers at all but the first leadership (content) session (i.e. weeks 4-11). The majority of ratings were positive, with mean scores of 1 or 2 (out of 5) on all dimensions suggesting that mothers concurred and found the sessions helpful, leaders good, and were likely to use what they had learnt. Some parents reported that sharing experiences with the group was not always easy.

All mothers who were interviewed were positive about the programme, underlining the importance of knowing that they

\footnotetext{
${ }^{5}$ Pattern Changing is an educational programme for abused women focusing on understanding the problem of abuse and its impact on families, learning new techniques for developing healthy patterns of living, and setting realistic goals (Goodman and Fallon 1995). The Freedom programme aims to help victims of domestic abuse understand what has happened to them and to consider the impact on children in the family (Craven 2008).
}

were not the only one in their situation and being able to take time out for themselves: "That was the thing each week that I looked forward to. I enjoyed being able to take that time out" [Parent 2]. Particular activities used in the programme such as the "jar of stars" ${ }^{6}$, were praised as being practical things that parents could use at home: "This complemented and enhanced all of the other support and advice I have had about parenting. It really enforced how good that approach was" [Parent 2].

Other activities were noted as being particularly useful for self-reflection; parents commented that they were "good because it makes you realise what you need to work on" [Parent 5] and that "imagery helps me realise I have support in other places if not from my parents" [Parent 9]. In the anonymous weekly feedback forms mothers noted things that they found useful about the session, including: "realising you can control things and... choose to focus attention on negative or positive things"; "thinking about beliefs and how they affect behaviour"; "understanding how we shape the future behaviour of our children"; and, "empowerment - things are possible; believe in yourself". Mothers also offered suggestions for programme improvement but these tended to reflect individual preferences rather than provide a consistent view, for example one found a session too busy, while another said that too much time was spent on vision boards; other parents said they valued this time.

The programme facilitators and managers also talked highly of the programme, and in particular recognised the value in having a programme focusing on the mothers themselves, for example: "It's about the women - most groups are about the children! Child First. This focused on them first" [Facilitator 2]. Another reflected that "there's something in it for everyone, no matter what stage of life you're at" [Facilitator 1]. The Head Teacher commented that "It's been transformative, it's been empowering... What I think that is so powerful about Family Vision... is that it can transform parents in terms of their aspirations for their own lives and therefore that's going to make a massive difference to their children". Both managers said that they would like to run Family Vision again; "It feels like it's a really strong programme. I'd hate to stop" [Centre Manager].

The length of the course and the sessions was thought by mothers to be mostly satisfactory, with one noting that she would have liked longer sessions, and another pointing out that any longer and it would have been difficult to attend due to work commitments. The size of the groups were also acceptable to mothers, both those who attended the Children's Centre course $(n=11)$ and those at the primary school $(n=6)$. Support offered by the facilitators when a session was missed

\footnotetext{
${ }^{6}$ The Jar of Stars activity is a family gratitude practice where parents notice and record positive things about their family on origami stars, which are collected and stored in a jar. They are encouraged to do this as regularly as possible.
} 
or mothers needed additional support was highlighted as useful for one or two parents in the larger group who wanted to explore things in more time than the session would allow. Mothers were keen for a follow-up course six months after the programme ends. One mother said: "We loved being together - learning, support, inspiration, having a brilliant leader to keep it focused" [Parent 11], and she feared it would all taper off quickly once the course ended.

An area for improvement raised by a number of mothers was communication. One mentioned that a lack of information about the course beforehand made it harder to justify time off to her employer, and another said that she would have liked more information about the course during the first couple of settling-in weeks. Three mothers also raised an issue with being referred to as 'single' or 'lone' parents, reporting that this felt too negative.

Acceptability for Domestic Violence Survivors At the Children's Centre, the manager acknowledged that most of the programmes they offer for parents with a history of experiencing domestic violence are for when they are still in crisis or focused on understanding their victimisation experience:

They [the programmes] are looking at you as a victim, or a survivor all the time. They are not looking at you outside of that role... I think that's what's so refreshing about FV... it's not focusing on that stuff at all really. It's looking forward... it gives a whole different perspective [Centre Manager].

Mothers said that the FV programme was useful in this context, for example: "the messages of motivation, confidence and finding your path was really helpful and you could connect it" [Parent 1]. Family Vision was seen as a programme that helped parents to look forward, and many mothers noted how useful this was to both them and their families. One stated that "the course gives you the tools to have a fresh start - a family mission statement. You don't have to fix everything. I've changed perspective, taken away judgement and others people's rules so I can make own" [Parent 8]. Others felt the same:

If you've never really been able to have your own vision, it is daunting to be able to get that. You're talking about a bunch of parents who have never $100 \%$ had control. The course helps you realise that you are capable and entitled to that. There was no tell your story session, which I think was good [Parent 7].

That said, a few mothers thought that depending on people's particular situations, it might be useful to attend a different course before attending Family Vision, which specifically focused on dealing with past experiences of violence, e.g.:
There wasn't a lot of focus on the past, so it would help if you had done something like Pattern Changing and dealing with the past. But some people wouldn't necessarily need that. If you're still thinking so much in the past, it's hard to look forward [Parent 5].

Mothers also stressed the importance of participants being in a similar situation and having "the head space to make it work as well as it can" [Parent 3]. A few said that the programme should be opened up to all parents, not just single parents or those who have experienced domestic violence.

We asked mothers about other programmes they had attended, and how Family Vision compared. The majority had attended at least one previous parenting and/or DVA course, and agreed that Family Vision offered something different to the others. Most mothers who had attended the DVA Pattern Changing course spoke highly of it, and felt that Family Vision complemented and built on this:

I came out of Pattern Changing feeling a little bit lost... my head was a lot clearer but I still had no idea where to go...trapped in that bubble of 'I'm the victim'. Family Vision gave us that next step about how to move forward [Parent 3].

You're left after Pattern Changing stuck, and you don't know how to go forward or have the means to. You need that I think. Before I went on this I hadn't been offered anything to help me move forward. I've felt in limbo for the last couple of years. It's only the things that help you go forward that help you deal with things in a different way [Parent 5].

I understood and benefitted more from Family Vision having done Pattern Changing. I was able to look at the future and the now, whereas Pattern Changing is all about the past. Family Vision would make a very good follow-up. The two could work very well together [Parent 6].

Being in a group where all parents had similar past experiences of domestic violence seemed to support mothers' willingness to share and take part in group activities, with one saying that "once you get to know the group and you listen to their stories it's a lot easier to open up" [Parent 4]. Others added that "if you're sitting there quietly you don't feel like you have to speak because they understand why you're tucked up inside of yourself that day" [Parent 6], and "the group made me reveal something very personal that I had not shared before and it was a huge relief to get it out" [Parent 10]. Both groups independently decided to set up their own social network group where they could communicate outside of the sessions. The mothers of the smaller group all reported bonding with the 
other parents and referred to themselves as 'The Tribe': "From a social bonding perspective it's been invaluable. We've been super lucky... we've all connected" [Parent 11].

Facilitator Training and Supervision Staff from each site were selected by the senior managers to be trained in the FV programme. In the Children's Centre, the manager reported that this decision was based largely on the availability of staff but that normally decisions are made based on individual strengths, experience and prior knowledge. She said that "it [Family Vision] is probably different from other interventions that Family Support Workers would be familiar with". In the school, the family worker was an obvious choice. If this role didn't exist, the Head Teacher said that someone from the senior leadership team or a teacher would have led it, perhaps with support from a Teaching Assistant. But she noted that "it's really about the person and their personality, and the community" [Head Teacher].

Feedback provided by the facilitators at the end of the training days confirmed that overall, they were happy with the training they had received and felt confident to deliver the programme themselves. All six trainees agreed that the training was clearly defined, the content was organised and easy to follow, and the objectives were met. Facilitators reflected that the training was delivered in a similar way to sessions run with parents, and highlighted the benefit of reflection and participation. After the two-day training, most facilitators said they would have liked the training to be longer but said that they felt confident to co-deliver the programme. Two facilitators said they would have liked to embed the learning more through practice during the training days.

In the post-intervention interviews with the facilitators, all noted that they felt more confident delivering sessions in the first half of the programme compared to the second. One facilitator said that it was important to consider this in future training because, in her view, "the turning point for parents comes later in the course" [Facilitator 1]. Providing time between training sessions to reflect on what they had learned was also suggested, rather than back-to-back training days. One facilitator said that she would have liked to have experienced the programme in full for herself before being trained to co-deliver. All agreed that co-delivering alongside the programme developer was beneficial, and one felt that the manual on its own was not sufficient to deliver the programme. One facilitator worried that young parents might not relate to her as well as the programme developer because she was an older woman and had not necessarily been though the same experiences as them: "[Programme developer] is someone they could aspire to be like" [Facilitator 3].

All facilitators reported finding the weekly supervision with the programme developer useful, and said that it helped with session planning for the next week as well as building the facilitators' relationship. The facilitators also said that being involved in delivery of the programme had impacted on their own professional practice. One facilitator reported using the ideas and ways of working in her subsequent day-to-day practice. Another noted:

[It made me] think more about people taking stock of their own lives and doing it for themselves a bit. I'm a bit of a fixer, I want to make it okay for people... sometimes you need to empower people to do it for themselves [Facilitator 3].

\section{Promise}

Table 4 presents the means and standard deviations for the sample where we had both baseline and post-intervention data for the WEMWBS $(n=15)$ and the PEEM $(n=14)$. The baseline mean including the four participants lost to postintervention follow-up was slightly higher at 42.3 (9.4) for the WEMWBS and 119.1 (23.1) for the PEEM. Participants made an average change of 38 points on the PEEM and 8 points on the WEMWBS. We did not conduct tests of significance.

Table 5 presents the results of two aspects of the parentchild relationship: conflict and closeness, as reported by mothers on 19 index parent-child relationships, where we had both baseline and post-intervention data on the same child/ren. The average change score was around 2 points difference between baseline and post-intervention, however baseline scores were high (positive) at the outset for warmth and closeness in the parent-child relationships. Finally, Table 5 also presents the findings of parent-reported child psychosocial difficulties on the SDQ, separated into children under four years of age and those between four and 16 years. The average score for children was in the 'abnormal' range (above 17), with over half the children meeting the threshold for clinically significant levels of difficulty. This had reduced by the post-intervention time point, although for older children the average score remained in the clinical or abnormal range.

Impact on Parents When asked during the interviews and focus groups what impact (if any) they considered the

Table 4 Empowerment and mental well-being in parent participants

\begin{tabular}{lll}
\hline & PEEM (n=14) & $\begin{array}{l}\text { WEBWMS } \\
(\mathrm{n}=15)\end{array}$ \\
\hline Baseline: Mean (SD) & $118.2(22.1)$ & $40.2(8.8)$ \\
Post-intervention: Mean (SD) & $156.5(26.9)$ & $48.4(9.8)$ \\
Change score: Mean (95\% CI) & $+38.3(17.7$ to 58.9) & $+8.2(-0.8$ to 17.2$)$ \\
\hline
\end{tabular}


Table 5 Conflict and closeness in parent-child relationships, and children's psychosocial functioning

\begin{tabular}{lll}
\hline & Conflict subscale $(\mathrm{n}=19)$ & $\begin{array}{c}\text { Closeness subscale }(\mathrm{n}=19) \\
29.5(5.0)\end{array}$ \\
Baseline & $23.3(6.6)$ & $31.3(3.7)$ \\
Post-intervention & $21.6(8.5)$ & $+1.8(-0.8$ to 4.4$)$ \\
Change score: Mean (95\% CI) & $-1.8(-4.2$ to 0.7$)$ & SDQ Children >4 years $(n=9)$ \\
& & $19.8(10.2)$ \\
Baseline: Mean (SD) & SDQ Children <4 years $(n=8)$ & $17.4(8.4)$ \\
Post-intervention: Mean (SD) & $16.6(7.6)$ & $-2.3(-8.5$ to 3.8$)$ \\
Change score: Mean (95\% CI) & $13.1(7.2)$ & $58.3 \%$ \\
\% meeting clinical threshold at baseline & $-3.5(-8.6$ to 1.6$)$ & $50 \%$
\end{tabular}

programme had had on their lives, mothers mentioned increased confidence, improved self-confidence in decisionmaking, increased resilience and strength of conviction. For example, one commented that "before it mattered to me too much what everyone else thought but the course made me realise it really mattered what I thought" [Parent 10]. Another said that they felt "more comfortable and confident in [their] own ability" [Parent 12] and another described the impact as follows:

Me finding me, and understanding my behaviour and why I believe these things. It probably has had a knock-on effect on the kids, if I'm more at peace with myself. I feel I can stand up for me again and I don't need to feel guilty about being there for me. Before it was all about the children or making other people happy [Parent 6].

One facilitator also commented on the change she witnessed in the mothers who attended the programme saying that "Some of them walk differently; I think it's amazing; you can see a physical transformation" [Facilitator 1].

Another impact of the programme highlighted by many of the mothers was having the time and space to think about the future and what they wanted for them and their family. One commented that "being more aware of what I want rather than focusing on what everyone wants, or think I should want. Being stronger in my own head... rather than letting someone else guide me, guide myself" [Parent 5]. Other parents felt similarly: "You are in control and you can change things. Knowing I have that, and someone having faith in you, was really positive" [Parent 2]; "It was almost like I found myself, which I had never had before" [Parent 11]; "'I'm no longer stuck in a rut. I actually know what I want to do and how to get there. Whereas before I had no motivation, nothing, to do anything" [Parent 4].

Two mothers said that Family Vision made them realise they need to have time for themselves and one decided that she would like to return to work; another to college:
I think my life has changed so much in the last year... I very much was looking at the past, and was very negative about everything. This was the turn-around for me, that I could make my life very different [Parent 2].

Impact on Children Mothers also noted the impact the programme had had on their child/ren, suggesting that in some cases it had improved relationships through an increased understanding of their child's needs. For example, one said:

I can understand my son more and why he is being the way he is. I'm analysing him, which I never would have dreamt of doing before. It means I'm getting less stressed as a whole the house is happier. He's still a monkey but he is happier and more loving [Parent 6].

Mothers also said it had affected their children via their own improved self-confidence as a person and a parent, and having new strategies to use, e.g.: "I've pulled myself together a bit which has helped pull him together" [Parent 1]; "I don't give up any more for an easy life. I'm more confident as a parent and a person... she can see I'm more confident in myself to stand up to her" [Parent 4].

The facilitators recalled the transformation they witnessed: "[Parent] said she realised that she could help her children herself, she didn't need anyone else to do it" [Facilitator 3]; and, "it was really helpful for the parents. It was so nice to see it doing what it said on the tin" [Facilitator 2].

\section{Discussion}

This is the first study to explore the feasibility and acceptability of a life coaching programme for parents following domestic violence and abuse. While life coaching has been used successfully as a behaviour change model in other contexts (Ammentorp 
et al. 2013), this study suggests that it is an acceptable approach to support women who are parenting alone after experiencing DVA. Furthermore, given the known links between improved parent well-being, quality of parenting, and child outcomes (Chiesa et al. 2018), it follows that such an approach may be a promising innovation to support children exposed to DVA.

There were positive indications from both the qualitative and quantitative data that the programme was feasible to deliver in community settings in England. In particular, referral and recruitment to the two groups was achieved in a short space of time, and retention to the programme was high. There remains a question about how to best identify and recruit the families most in need; the school-based group struggled to engage parents in that community who they considered a priority. However, this may reveal instead a disparity between service provider's and parents' views about when and what an appropriate intervention is for a family at a given point in time (e.g. Wilson 1993). Participating mothers reflected on a need to be in the right 'headspace' for the programme. So-called 'hard to reach' families who do not engage may in fact be making rational judgements about the utility of such programmes for themselves, and providers may need to be more personalised in the timing of their offers, i.e. a refusal now does not mean a family can't be referred again later.

Neither the mothers nor the children included in this study were screened for levels of difficulty as an entry/inclusion criteria, however, consistent with the literature, the baseline outcome data suggest that recruitment procedures still yielded a DVA sample with very low levels of well-being and empowerment (parents) as well as poor psychosocial functioning (children). It is not possible to make inferences about the effectiveness of the intervention at this stage, however, the change scores for the outcomes measured are promising and support a case for a larger study powered to assess the impact on mothers and children. In contrast to some literature (McCarty et al. 2003), in this sample the data do not suggest that poor parent-child relationships underlie the pathway from poor maternal mental health and well-being to psychosocial difficulties; parenting capacity and skills may be a more predictive construct to measure in future evaluation.

Themes arising from the qualitative data suggested some key areas for development of the FV programme before further testing: a more intensive training experience for facilitators, with opportunities to both observe and practice delivery of the programme; improved pre-course information about the programme for parents and sufficient time for engagement with vulnerable parents during the referral and recruitment stage; and further consideration about how a wider array of referring agencies can be better supported to appropriately identify target group parents. Although only one referred mother was considered ineligible for the intervention, the FV facilitators fielded a number of calls from professionals seeking help for families in continuining crisis underlining the limited availability of community services to support parents in this context.
Acceptability of the programme by the participants was high with positive ratings across the board on the FV sessions, quality of delivery and likelihood of applying the ideas. Underlining the therapeutic power of groups, and the mechanisms of change explored by Yalom and colleagues (Vinogradov et al. 2003), mothers reflected positively on the connections with other parents and support network benefits. Although mothers, facilitators and service managers alike agreed that FV is acceptable for families who have experienced domestic violence, there remains a question about the additional support that parents may require either before, during or after receiving FV. Family Vision does not attempt to explore or deal with women's past experiences of violence and associated trauma; its focus is squarely on the building leadership for parenting. Approximately half of the mothers in this study came to FV having already received specialist DVA support, while the others had had no input from services in this regard. While not imparting parenting skills training per se or working therapeutically with DVA experiences, FV may provide the platform for more effective engagement with other support on offer in the community by illuminating the families' needs, the resources required to achieve their vision and the terms of their engagement with others.

Most innovations rely on the singular passion and dedication of their developer, a necessary force for their growth but potentially restrictive for their replication. In the early days of programme testing, evaluators face the task of disentangling the intervention from its creator, isolating the unacknowledged qualities that the developer brings to programme delivery that may influence the transferability and effectiveness of the intervention (see Moore et al. 2014). Family Vision is unlikely to be different in that regard; parents and facilitators repeatedly acknowledged the FV programme developer in their reflections about the impact the programme had had, signalling her as a role model. While this study has demonstrated that it is feasible to train service provider staff to successfully codeliver FV, future research will need to establish it can be replicated without the developer at the healm.

\section{Conclusion}

This study tested the acceptability and feasibility of the FV programme but did not examine the feasibility of a larger effectiveness evaluation. A pilot trial is now required to consider the barriers to wider scale-up and to test procedures necessary for a definitive trial, incuding the acceptability of randomisation. If effective, the FV programme has the potential to fill an important gap in efforts to support parents raising children who have been exposed to traumatic family breakdown and DVA. 
Acknowledgements This study was funded by an Economic and Social Research Council (ESRC) Impact Acceleration Account award from the University of Exeter.

Vashti Berry's time was supported by the National Institute for Health Research (NIHR) Collaboration for Leadership in Applied Health Research and Care South West Peninsula. The views expressed are those of the author(s) and not necessarily those of the NHS, the NIHR or the Department of Health and Social Care.

Due to ethical concerns, the research data supporting this publication are not publicly available.

Open Access This article is distributed under the terms of the Creative Commons Attribution 4.0 International License (http:// creativecommons.org/licenses/by/4.0/), which permits unrestricted use, distribution, and reproduction in any medium, provided you give appropriate credit to the original author(s) and the source, provide a link to the Creative Commons license, and indicate if changes were made.

Publisher's Note Springer Nature remains neutral with regard to jurisdictional claims in published maps and institutional affiliations.

\section{References}

Ammentorp, J., Uhrenfeldt, L., Angel, F., Ehrensvärd, M., Carlsen, E. B., $\&$ Kofoed, P.-E. (2013). Can life coaching improve health outcomes?-a systematic review of intervention studies. BMC Health Services Research, 13(1), 428.

Austin, A. E., Shanahan, M. E., Barrios, Y. V., \& Macy, R. J. (2018). A systematic review of interventions for women parenting in the context of intimate partner violence. Trauma, Violence, \& Abuse, 152483801771923. https://doi.org/10.1177/1524838017719233.

Axford, N., Lehtonen, M., Kaoukji, D., Tobin, K., \& Berry, V. (2012). Engaging parents in parenting programs: Lessons from research and practice. Children and Youth Services Review, 34, 2061-2071.

Chiesa, A. E., Kallechey, L., Harlaar, N., Rashaan Ford, C., Garrido, E. F., Betts, W. R., \& Maguire, S. (2018). Intimate partner violence victimization and parenting: A systematic review. Child Abuse \& Neglect, 80, 285-300.

Clarke, A., Friede, T., Putz, R., Ashdown, J., Martin, S., Blake, A., et al. (2011). Warwick-Edinburgh mental well-being scale (WEMWBS): Validated for teenage school students in England and Scotland. A mixed methods assessment. BMC Public Health, 11(1), 487.

Craven, P. (2008). Living with the dominator: A book about the freedom Programme. In Bayswater. Australia: Freedom Publishing.

Cummings, T. G., \& Worley, C. G. (2009). Coaching and mentoring Mason, $\mathrm{OH}$ : South-Western Cengage Learning.

Driscoll, K., \& Pianta, R. C. (2011). Mothers' and Fathers' perceptions of conflict and closeness in parent-child relationships during early childhood. Journal of Early Childhood \& Infant Psychology, 7, 1-24.

Evans, S. E., Davies, C., \& DiLillo, D. (2008). Exposure to domestic violence: A meta-analysis of child and adolescent outcomes. Aggression and Violent Behavior, 13(2), 131-140.

Farr, N. (2017). Family vision: Facilitators' manual. In Unpublished Programme manual. UK: Exeter.

Farr, N. (2018). I am the Parent Who Stayed: Joyfulfully Parenting Alone. Great Britain: Practical Inspiration Publishing.

Freiberg, K., Homel, R., \& Branch, S. (2014). The parent empowerment and efficacy measure (PEEM): A tool for strengthening the accountability and effectiveness of family support services. Australian Social Work, 67(3), 405-418.
Goodman, R. (2001). Psychometric properties of the strengths and difficulties questionnaire. Journal of the American Academy of Child \& Adolescent Psychiatry, 40(11), 1337-1345.

Goodman, \& Fallon, B. C. (1995). Pattern Changing for Abused Women: An Educational Program (Vol. 9). California: SAGE Publications, Inc.

Goodman, R., Meltzer, H., \& Bailey, V. (1998). The strengths and difficulties questionnaire: A pilot study on the validity of the self-report version. European Child \& Adolescent Psychiatry, 7(3), 125-130.

Gov.UK (2017). Domestic violence and abuse [Accessed 4 Sept 2018].

Graham-Bermann, S. A., \& Perkins, S. (2010). Effects of early exposure and lifetime exposure to intimate partner violence (IPV) on child adjustment. Violence and Victims, 25(4), 427-439. https://doi.org/ 10.1891/0886-6708.25.4.427.

Guy, J., Feinstein, L., \& Griffiths, A. (2014). Early intervention in domestic violence and abuse. Retrieved from London. In United Kingdom.

Howarth, E., Moore, T. H. M., Welton, N. J., Lewis, N., Stanley, N., MacMillan, H., et al. (2016). IMPRoving outcomes for children exposed to domestic ViolencE (IMPROVE): An evidence synthesis. Public Health Research, 4(10), 1-342.

Jack, S. M., Ford-Gilboe, M., Wathen, C. N., Davidov, D. M., McNaughton, D. B., Coben, J. H., . . MacMillan, H. L. (2012). Development of a nurse home visitation intervention for intimate partner violence. BMC Health Services Research, 12(1), 1952.

Jarosz, J. (2016). What is life coaching? An integrative review of the evidence-based literature. International Journal of Evidence Based Coaching \& Mentoring, 14(1), 34-56.

Kitzmann, K. M., Gaylord, N. K., Holt, A. R., \& Kenny, E. D. (2003). Child witnesses to domestic violence: A meta-analytic review. Journal of Clinical Psychology, 71(2), 339-352.

Lapierre, S. (2008). Mothering in the context of domestic violence: The pervasiveness of a deficit model of mothering. Child \& Family Social Work, 13(4), 454-463.

Lapierre, S. (2010a). More responsibilities, less control: Understanding the challenges and difficulties involved in mothering in the context of domestic violence. British Journal of Social Work, 40(5), 1434 1451. https://doi.org/10.1093/bjsw/bcp080.

Lapierre, S. (2010b). Striving to be 'Good' mothers: Abused Women's experiences of mothering. Child Abuse Review, 19(5), 342-357. https://doi.org/10.1002/car.1113.

Leimon, A., Moscovici, F., \& Goodier, H. (2011). Coaching Women to Lead. East Sussex: Routledge.

Letourneau, Drummond, J., Fleming, D., Kysela, G., McDonald, L., \& Stewart, M. (2001). Supporting parents: Can intervention improve parent-child relationships? Journal of Family Nursing, 7(2), 159-187.

Letourneau, Fedick, C. B., \& Willms, J. D. (2007). Mothering and domestic violence: A longitudinal analysis. Journal of Family Violence, 22(8), 649-659. https://doi.org/10.1007/s10896-007-9099-6.

McCarty, C. A., McMahon, R. J., \& Conduct Problems Prevention Research Group. (2003). Mediators of the relation between maternal depressive symptoms and child internalizing and disruptive behavior disorders. Journal of Family Psychology, 17(4), 545-556.

Moore, G., Audrey, S., Barker, M., Bond, L., Bonell, C., Hardeman, W., et al. (2014). Process evaluation of complex interventions: Medical Research Council guidance. London: MRC Population Health Science Research Network.

NHS Scotland (2006). The Warwick-Edinburgh Mental Well-being Scale (WEMWBS). Edinburgh, UK: NHS Health Scotland, University of Warwick, University of Edinburgh.

Pianta, R. C. (1992). Child-parent relationship scale. Charlottesville, VA: University of Virginia.

SAMHSA (2014). SAMHSA's Working Concept of Trauma and Framework for a Trauma -Informed Approach, National Centre for Trauma-Informed Care (NCTIC). SAMHSA, Rockville.

Stein, M. B., \& Kennedy, C. (2001). Major depressive and post-traumatic stress disorder comorbidity in female victims of intimate partner 
violence. Journal of Affective Disorders, 66(2-3), 133-138. https:// doi.org/10.1016/s0165-0327(00)00301-3.

Stober, D. R., \& Grant, A. M. (2006). Toward a contextual approach to coaching models. New York: John Wiley \& Sons.

Vinogradov, S., Cox, P. D., \& Yalom, I. D. (2003). Group therapy. In R. E. Hales \& S. C. Yudofsky (Eds.), The American Psychiatric Publishing textbook of clinical psychiatry (pp. 1333-1371). Arlington: American Psychiatric Publishing, Inc.

Wilson, G. (1993). Users and providers: Different perspectives on community care services. Journal of Social Policy, 22(4), 507-526.
Wolfe, D. A., Crooks, C. V., Lee, V., McIntyre-Smith, A., \& Jaffe, P. G. (2003). The effects of children's exposure to domestic violence: A meta-analysis and critique. Clinical Child and Family Psychology Review, 6(3), 171-187.

Zlotnick, C., Johnson, D. M., \& Kohn, R. (2006). Intimate partner violence and long-term psychosocial functioning in a national sample of American women. Journal of Interpersonal Violence, 21(2), 262275. https://doi.org/10.1177/0886260505282564. 